NASA Contractor Report 179646

\title{
Optical Strain Measurement System Development
}

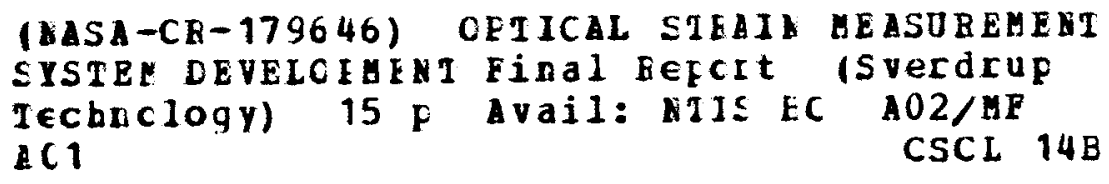

$\begin{array}{ll}\text { Unclas } \\ 63 / 35 & \text { CC87712 }\end{array}$

N87-26326

Christian T. Lant and Walid Qaqish

Sverdrup Technology, Inc.

Lewis Research Center

Cleveland, Ohio

July 1987

Prepared for

Lewis Research Center

Under Contract NAS3-24105

\section{NMsn}

National Aeronautics and

Space Administration 


\title{
OPTICAL STRAIN MEASUREMENT SYSTEM DEVELOPMENT
}

Christian T. Lant and Walid Qaqish

Sverdrup Technology, Inc.

Lewis Research Center

Cleveland, Ohio 44135

\begin{abstract}
SUMMARY
A laser speckle, differential strain measurement system has been built and tested for future applications in hostile environments. One-dimensional electronic correlation of speckle pattern movement allows a quasi-real time measure of strain. The system has been used successfully to measure uniaxial strain reaching into plastic deformation of a test specimen, at temperatures ranging to $450^{\circ} \mathrm{C}$. A resolution of 16 microstrain is given by the photodiode array sensor pitch and the specimen to sensor separation. The strain measurement error is estimated to be \pm 18 microstrain \pm 0.3 percent of the strain reading. The upper temperature limit of the gauge is determined by air density perturbations causing decorrelation of the reference and shifted speckle patterns, and may be improved by 1 imiting convective flow in the immediate vicinity of the test specimen.
\end{abstract}

\section{INTRODUCTION}

This paper covers the Phase I results of a multiphase effort to develop an optical strain gauge capable of mapping the principal axes of strain on the surface of a hot specimen. Durability enhancement programs for propulsion system components prompted the need for such instrumentation. The objective of this first phase has been to provide a noncontact, single axis, differential strain gauge for experimental purposes. Sverdrup Technology, Inc. is developing this optical strain measurement system for the Lewis Research Center.

The design of the optical strain gauge is based on the speckle shift method of Ichirou Yamaguchil at The Institute of Physical and Chemical Research, Japan. Laser speckle is a phase effect caused by the diffuse reflection of spatially coherent light off of a rough surface. Interference of the light reflected off of a specimen results in a light and dark intensity distribution at the sensor. Yamaguchi's noncontact method of measuring differential surface strain makes use of speckle field displacements detected by crosscorrelating electrical signals from a linear photodiode array. A limiting geometry makes speckle displacement due to stress on a test specimen directly proportional to the assoclated strain. Use of this method eliminates problems usually caused by subjecting conventional measurement devices to hostile environments such as extreme temperatures, and high electromagnetic fields; the sensor need not be in the same environment as the specimen. In addition, Yamaguchi's method has the advantages over other optical strain measurement techniques of not only being noncontacting, but needing no surface preparation, automatically correcting for strain error due to rigid body motion, and giving quasi-real time results (the value of strain is calculated within seconds of taking the data). 
THEORY

The utilization of laser speckle to determine differential strain is achieved by applying the Fresnel-Kirchhoff diffraction integral describing the propagation of light in free space. This integral is used to derive the relationship between surface deformation of a specimen subject to loading and speckle displacement in the diffraction field (refs. 1 and 2). The speckle displacement contains terms of transiation, rotation, and strain, from which the principle strain term must be extracted. This extraction relies on the use of two symmetrically incident laser beams reflected sequentially onto a linear photodiode array oriented parallel to the specimen surface. After the reference (before-strain) and shifted (after-strain) speckle patterns from each beam are recorded and correlated, the difference in speckle shift between them is taken leaving only the component of shift due to surface strain.

The theory interpreting the speckle displacement on the observation plane is based on the assumption that the flluminated region of the specimen is homogeneous; this region acts as a random diffraction grating. For speckle shift to accurately represent strain then requires that the change in the surface roughness spacing be uniform. This proved to be the case in the experimentation within the elastic limit of the test specimen, as observed in the stability of the speckle patterns and the agreement of the results with known quantities.

Referring to the simplified coordinate system shown in figure 1, a laser beam is incident on the diffuse surface of a test specimen at an angle $\theta_{5}$ from the normal to the surface. The observation plane is the $X, Y$ plane, and the object plane is the lowercase $x, y$ plane. The center of the incident laser spot is at the origin of the $x, y$ plane. When the object is stressed and deformed, the object point is displaced by $\vec{a}(x, y)$. The radius of curvature of the wavefront is denoted $L_{S}$. The speckle displacement $\vec{A}$ is broken down into components, given by

$$
\begin{gathered}
A_{X}=a_{x}-L_{0}\left[\varepsilon_{x x} \sin \left(\theta_{S}\right)-\Omega_{y}\left[\cos \left(\theta_{S}\right)+1\right]\right] \\
A_{Y}=a_{y}-L_{0}\left[\varepsilon_{x y} \sin \left(\theta_{S}\right)-\Omega_{x}\left[\cos \left(\theta_{S}\right)+1\right]-\Omega_{z} \sin \left(\theta_{S}\right)\right]
\end{gathered}
$$

where $\overrightarrow{\mathrm{a}}, \vec{\Omega}$, and $[\widetilde{\varepsilon}]$ are the translation vector, the rotation vector, and stain tensor, respectively. As long as the displacement $A_{y}$ is much smaller than the sum of the sensor height and the typical speckle size on the sensor $A_{x}$ can be determined by cross-correlating the sensor signals before and after surface deformation. The correlation is performed between the reference and the shifted speckle patterns from the left incident beam, and again between the reference and the shifted patterns from the right incident beam.

Initial cancellation of rigid body motion terms requires the incident radius of curvature $L_{S}$ to be much greater than the sensor distance $L_{0}$, and $L_{0}$ to be much greater than the spot diameter of the incident beam. Equations (i) show the remaining rigid body motion components in $A_{X}$, which can be cancelled out by taking the difference between speckle displacements from the two beams at $+\theta_{S}$ and $-\theta_{S}$. From equation (1.a) then 


$$
\Delta A_{X}=-2 L_{0} x_{x} \sin (\theta) \quad\left(\text { where } \theta=\left|\theta_{S}\right|\right)
$$

or,

$$
\varepsilon_{x x}=\frac{-\Delta A_{X}}{2 L_{0} \sin (\theta)}
$$

If the criterion $L_{0} / L_{S} \ll 1$ is not met, then the out-of-plane error term

$$
\text { error term }=\left[\frac{-a_{z} \cos (\theta)}{L_{S}}\right]
$$

is added to the strain formula (eq. (3)).

\section{MEASUREMENT SYSTEM DESIGN AND SETUP}

The system is designed to run predominantly under computer control, with the operator selecting procedures from menus on the CRT. A schematic of the optical setup is depicted in figure 2. The laser and the beamsteering components are mounted on a hard-coupled optical table (this non-interferometric technique does not require vibration isolation). Two variable beamsplitters are used to create three beam paths, each beam switched by an acousto-optic modulator. A line scan camera records the speckle patterns generated by the left and right beams at $\theta_{S}=45^{\circ}$, and an area array camera allows the test section and gauge position to be monitored remotely. The cameras, modulators, and the motorized mirror mounts are remotely controlled. The testing machine and induction heater are mounted on a hydraulic lift table to provide positioning relative to the optics. An error analysis of this system shows an overall strain measurement error estimate of \pm 18 microstrain \pm 0.3 percent of the strain reading.

The control and data paths are shown in figure 3 . The system controller initiates procedures through three main components, these being the data acquisition/control unit (DAQ), and two pulse generators. The data acquisition/ control unit outputs control signals to the custom circuitry used for exposing and reading the linear and area array cameras; these circuits synchronize the pulse generators with the array cameras, triggering the pulse generators to output TTL exposure pulses to the acousto-optic modulator RF generators. The triggered outputs of the pulse generators switching on and of $f$ the beamdeflecting modulators act as high speed programmable shutters. The DAQ is also used to read the voltages from thermocouples, resistance strain gauges on the specimen, and a load cell. Higher temperatures are also measured by the infrared pyrometer which, in addition, provides a temperature control signal to the induction heater. This allows precise control of the specimen temperature at the gauge position.

\section{RESULTS AND RECOMMENDATIONS}

A series of test results shown in the following paragraphs give a good indication of the overall system response. A 750 diode cross section of each speckle pattern is used in the correlations in order to minimize the execution 
time of the measurement. A typical pair of speckle patterns (reference and shifted) and their cross-correlation function is shown in figures 4 (a) and (b). The shift between the speckle patterns was induced by a $13.8 \mathrm{MPa}$ ( $2 \mathrm{ks} 1$ ) load. The shift $A_{x}$ was calculated to be 7 diodes $(105 \mu \mathrm{m})$, corresponding to 65 microstrain on the specimen after rigid body shift was cancelled out. The correlation curve was not normalized, in order to decrease the execution time involved.

Some plots of typical data runs are shown in figures 5 to 8 . These figure show data for isothermal runs at room temperature and $450^{\circ} \mathrm{C}$, as well as a run measuring thermal strain. All optical data shown here were taken by summing incremental shifts between each point. A load offset was applied to the specimen before each run; therefore, the stress axes do not represent an absolute value of stress. The test specimens are made from Inconel 600 stock, an alloy used for high temperature applications.

\section{Results}

Tests conducted during this program verified the stability of speckle patterns generated by an oxidized specimen subject to maximum strains over 0.1 percent. The stability of the surface structure of the specimen was not observed to be affected by high temperature once oxidation occurred. The tests were conducted in an open air atmosphere.

Figure 5 shows the optical gauge data plotted alongside the data from a resistance strain gauge taken at the same time. The curves can be seen to enter the nonlinear region of strain, and their slopes agree to within 6 percent. An offset of 6.9 to $13 \mathrm{MPa}(1.0$ to $2.0 \mathrm{ks} \dagger)$ occurs at the beginning of the run, where no strain is measured opticaliy. This offset (initially large slope) is typical of the optical measurements at the start of the load cycle, and is believed to be caused by movement of the specimen at small angle deflections of the eccentric crank connected to the load arm of the testing machine.

In figures 6(a) and (b), hysteresis due to plastic strain is observed in both the optical and resistance gauge data as the load is first increased to $262 \mathrm{MPa}(38 \mathrm{ks} 1$ ) and then backed down to the initial preset value. Both sets of data were generated on the same run. Figure $6(a)$ shows the plots of the optical gauge data, and figure $6(b)$ shows the corresponding resistance gauge data. Agreement between the two gauges is very good, with the final offset strain values of the optical and resistance gauges within 2 microstrain of each other. This is well within the resolution of both gauges. Curve fitting over the linear portions of the data show differences of 8 percent on the load up cycle and 3 percent on the load down cycle.

The optical data curve is discontinuous at the beginning of the load down cycle, due to the out-of-plane displacement term $a_{z}$. This type of break in the curve is often observed as the load is relaxed and the specimen returns to its neutral, unloaded position along the $z$ axis. In figure $6(a)$, the $a_{z}$ offset on the load down cycle is nearly equal to the sum of the az offsets in the opposite direction during the load up cycle. The remaining az displacement is spread smoothly along the curve as a function of load. It is observed that when the plots from each gauge are superposed and offset to align the load down curves, the slope signatures are the same. 
Figure 7 shows stress-strain data at high temperature; the temperature setpoint was $450^{\circ} \mathrm{C}$. The straight line drawn on the plot is the modulus of elasticity $E\left(T=450^{\circ}\right)$ given by an Inconel 600 data sheet. The slope calculated from the optical gauge data is 10 percent higher than the handbook value. The optical data show discontinuities below $67 \mathrm{MPa}(10 \mathrm{ks})$ due to specimen shifting in the $z$ direction $\left(a_{z}\right)$, but smooths out for a constant slope up to $200 \mathrm{MPa}(29 \mathrm{ks} 1)$. At high loads, the term $a_{z}$ has been observed to increase proportionally with load, which accounts for the slightly larger slope of the optical data.

A test run measuring thermal strain is shown in figure 8 . As with the isothermal runs, poor correlation occurred at temperatures above $450^{\circ}$, and the run was terminated. A linear $f t t$ of the data gives the measured coefficient of expansion to be $14.3 \mu \mathrm{m} / \mathrm{m}^{\circ} \mathrm{C}$. This is with in 3 percent of the handbook value. Some random error $( \pm 14.8 \mu \mathrm{m} / \mathrm{m})$ occurred due to the uncertainty in the temperature setpoint value.

A least-squares regression over the linear portion of the stratn data taken for each run provides a good measure of the accuracy of the data. The calculated modulus of elasticity (E) or coefficient of thermal expansion shows error trends in the system (e.g., the error due to $a_{z}$ increasing with load). The inear-correlation coefficient indicates the degree of confidence in $E$, or how well strain is shown to be a function of stress. The plots shown here have linear-correlation coefficients ranging from 0.998 to 1.000 .

\section{Phase I Conclusion and Phase II Design}

The experimentation conducted during this project has resulted in a number of useful insights regarding the implementation of Yamaguchi's theory. Overal1, this measurement system works very well for measuring strain at low to midrange temperatures (up to $450^{\circ} \mathrm{C}$ ) using an open air specimen configuration. Increasing the temperature range depends on how well air density perturbations in the vicinity of the specimen can be controlled. These perturbations cause time-varying speckle intensity fluctuations which lead to a relative shift between the left and right correlation functions. The temperature range could be increased by placing baffles in the vicinity of the heated specimen, or by enclosing the specimen, which would block convective air flow and decrease transverse thermal gradients between the specimen and the sensor.

The most practical result of the testing, though, is that the effectiveness of Yamaguchi's speckle shift technique as a strain gauge is limited by the extent of the system's immunity to rigid body motion of the test specimen. Thus, the limiting factors in implementing the test system are terms of rigid body motion. An increase in the radius of curvature of the laser beam wavefront, as well as careful alignment of the specimen in the load train, can eliminate the systematic error observed in these tests and ensure the reliability of the data with minimum equipment specifications. The present system contributes an out-of-plane error term (eq. (4)) of $0.13 \mathrm{a}_{z}$ strain to the measurement. The $a_{z}$ sensittvity can be decreased sufficiently by increasing the radius of wavefront curvature $L_{S}$. For the case of a test situation where translations of the test components are extreme and unavoidable, the $a_{z}$ translation term could be measured for each pair of speckle patterns recorded and calculated out of the speckle shift equation. 
The other effect of rigid body motion is decorrelation of the reference and shifted speckle patterns. This is caused primarlly by a prohibitively large component of shift in the vertical direction $\left(A_{Y}\right)$. As Ay increases, the amount of common information between the reference and shifted speckle patterns as recorded by the photodiode array becomes less and less. If Ay is a slowly varying function with respect to load, then decorrelation can be avoided by incrementing the load in small steps, and summing the strains as the reference patterns are updated. The sensitivity to $A_{y}$ can also be decreased by placing a cylindrical lens between the specimen and the linear photodiode array.

The second phase of the Optical Strain Measurement System Development is in progress. A schematic of the proposed Phase II system is shown in figure 9. The Phase II system design allows the plane of incidence to rotate about the $z$ axis. Since the intersection of the plane of incidence with the specimen surface defines the sensitive axis of the gauge, rotation of the plane of incidence enables multiple components of strain to be measured and the principal strain axes to be calculated. A single beam is switched between the two incident paths by a Pockels cell and polarizing beamsplitter cube combination.

Rotational invariance between the fixed and rotating assemblies is achieved by a pair of $1 / 4$ wave plates. The radius of curvature $L_{S}$ of the incident beam is increased by two orders of magnitude by a lens system which positions the beam waist at the specimen surface.

\section{REFERENCES}

1. I. Yamaguchi, A Laser-speckle Strain Gauge, J. Phys. E.: Sci. Instrum. 14 (1981).

2. I. Yamaguchi, Speckle Displacement and Decorrelation in the Diffraction and Image Fields for Small Object Deformation, Optica Acta 28(10) (1981). 


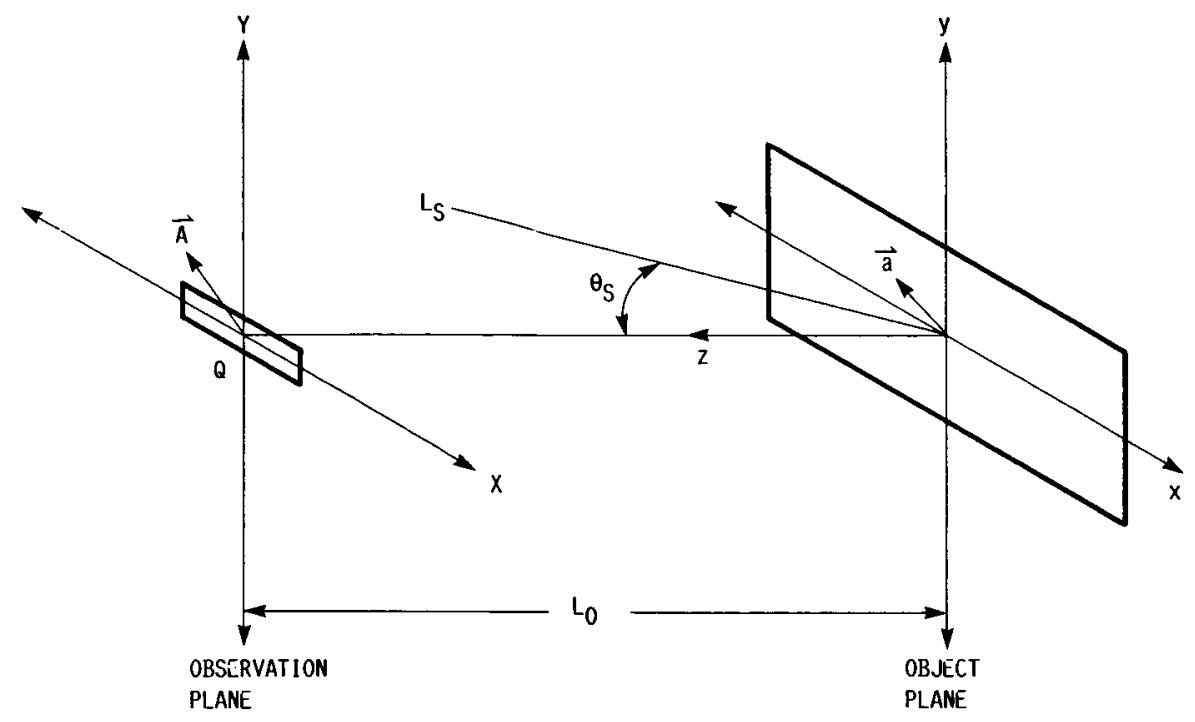

FIGURE 1. - SIMPLIFIED COORDINATE SYSTEM.

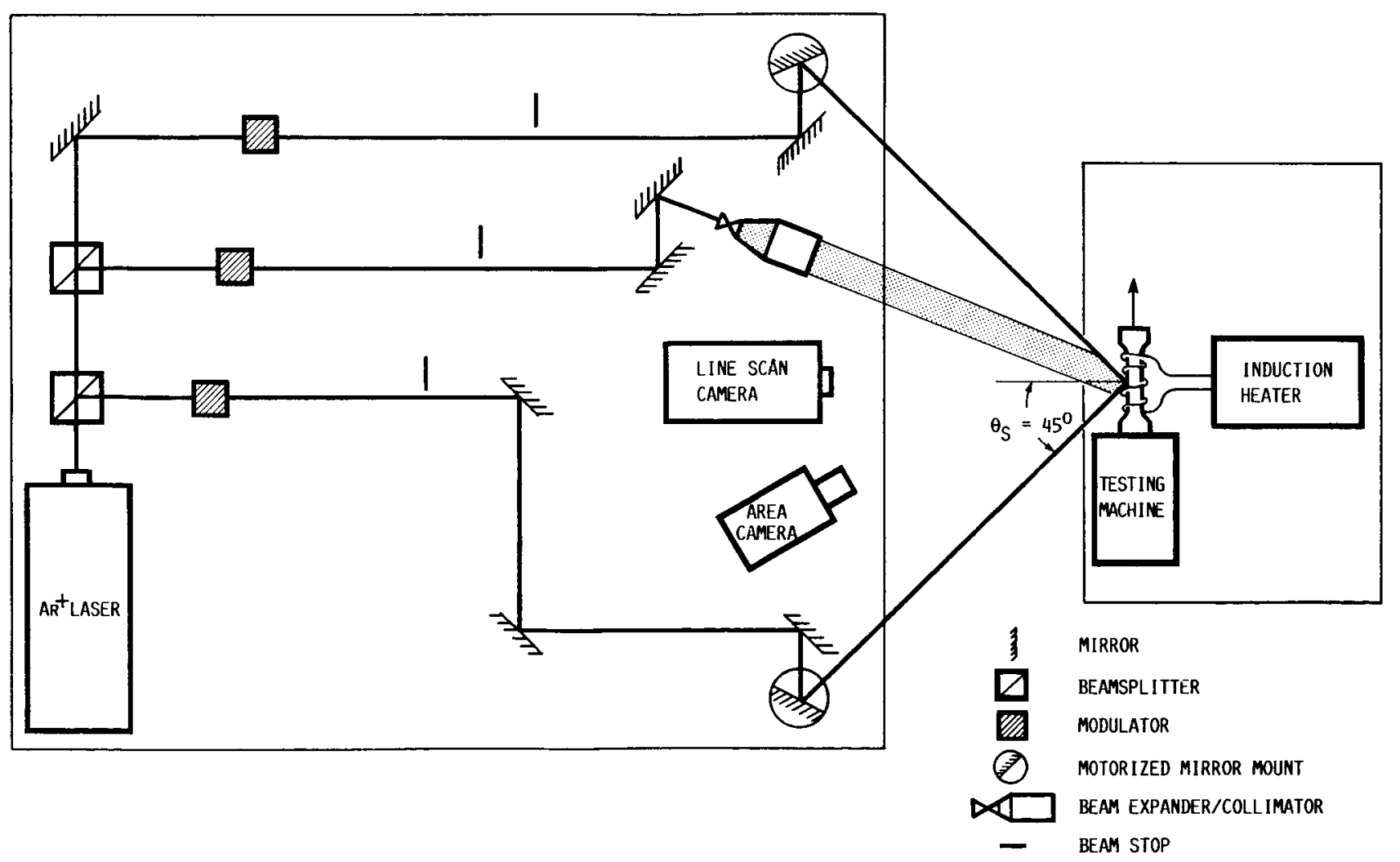

FIGURE 2. - OPIICAL SETUP AND TEST EQUIPMENT. 


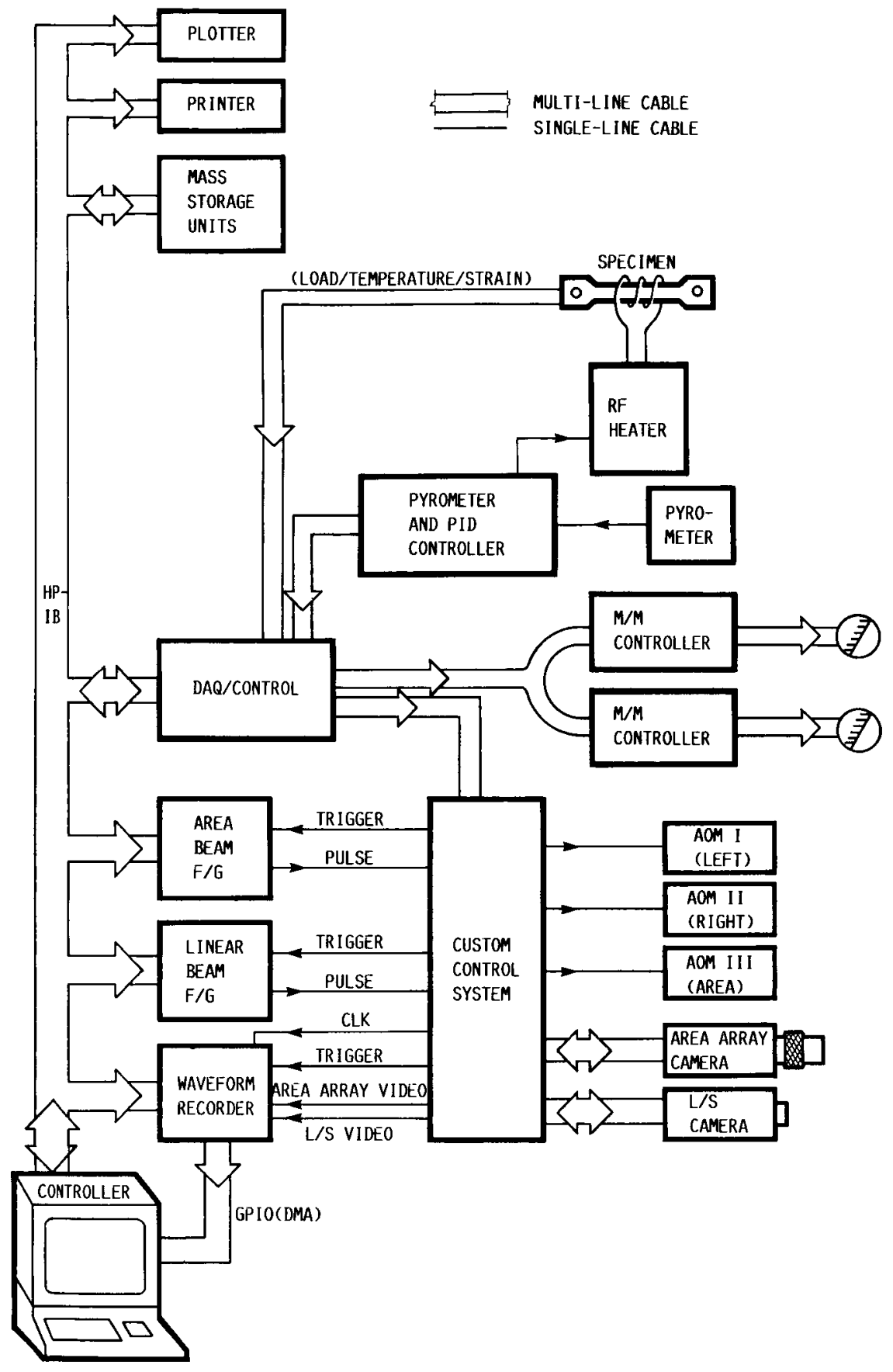

FigURE 3. - BLOCK DIAGRAM OF THE CONTROL/DATA ACQUISITION SYSTEM. 


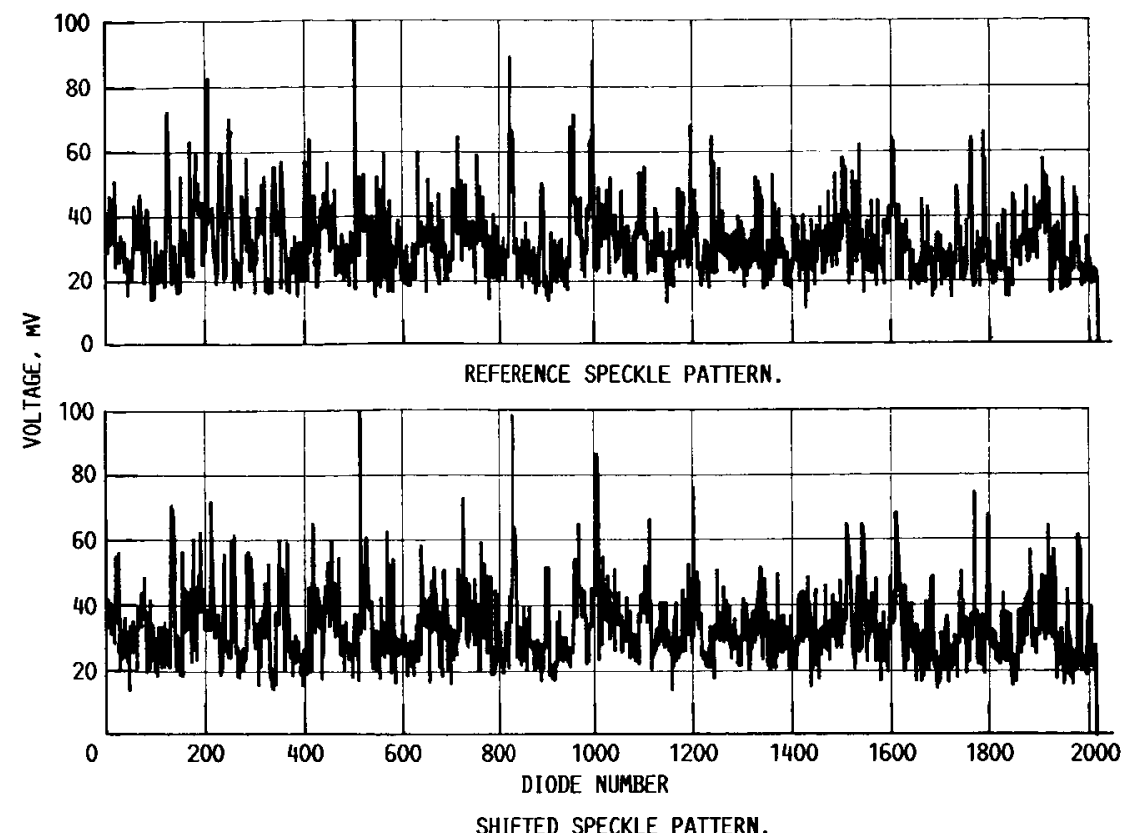

FIgURE 4A. - A TYPICAL PAIR OF REFERENCE AND SHIFTED SPECKLE PATTERNS.

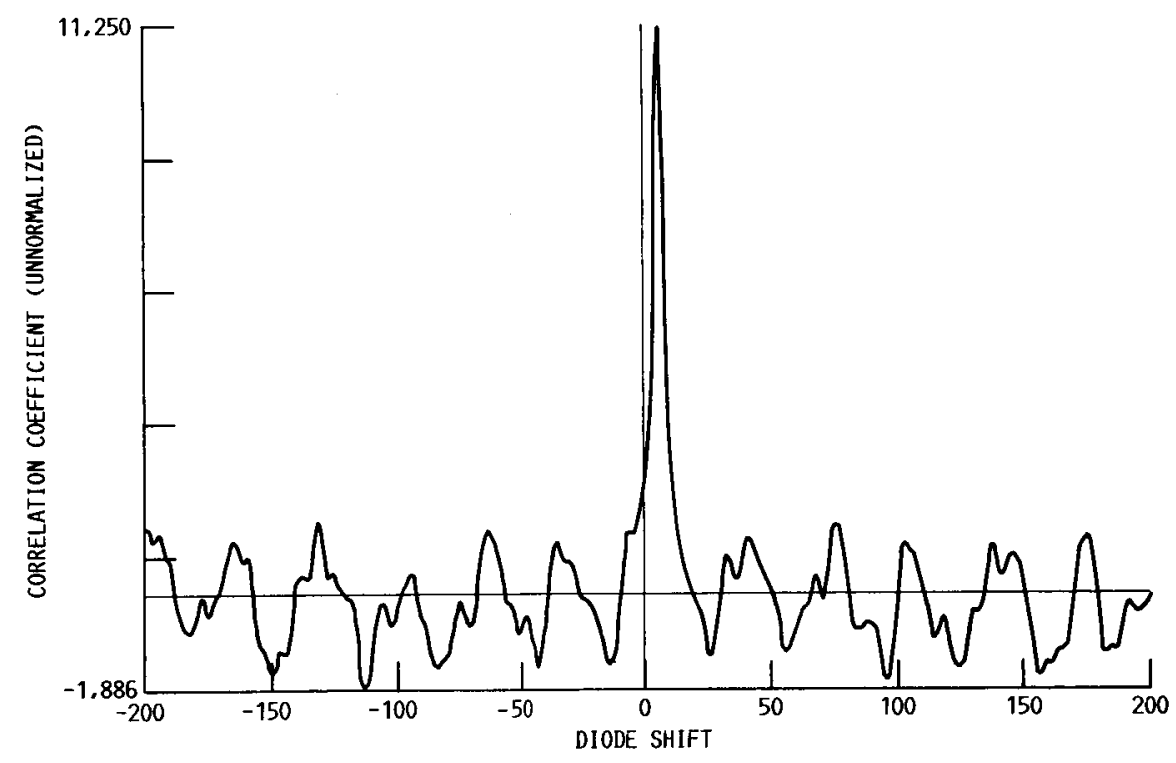

FIGURE 4B. - THE CORRELATION CURVE FOR THE SPECKLE PATTERNS IN FIGURE 4 A. 


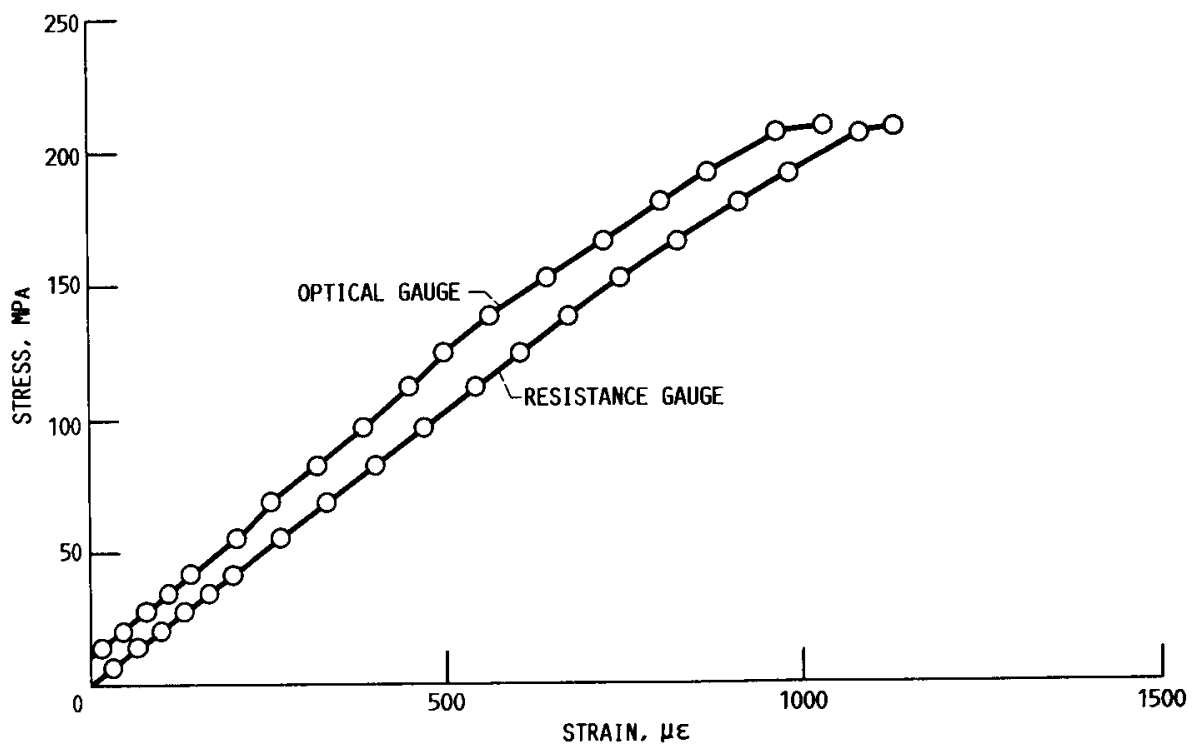

FIGURE 5. - COMPARISON OF THE OPTICAL GAUGE WITH A RESISTANCE GAUGE AT ROOM TEMPERATURE. 


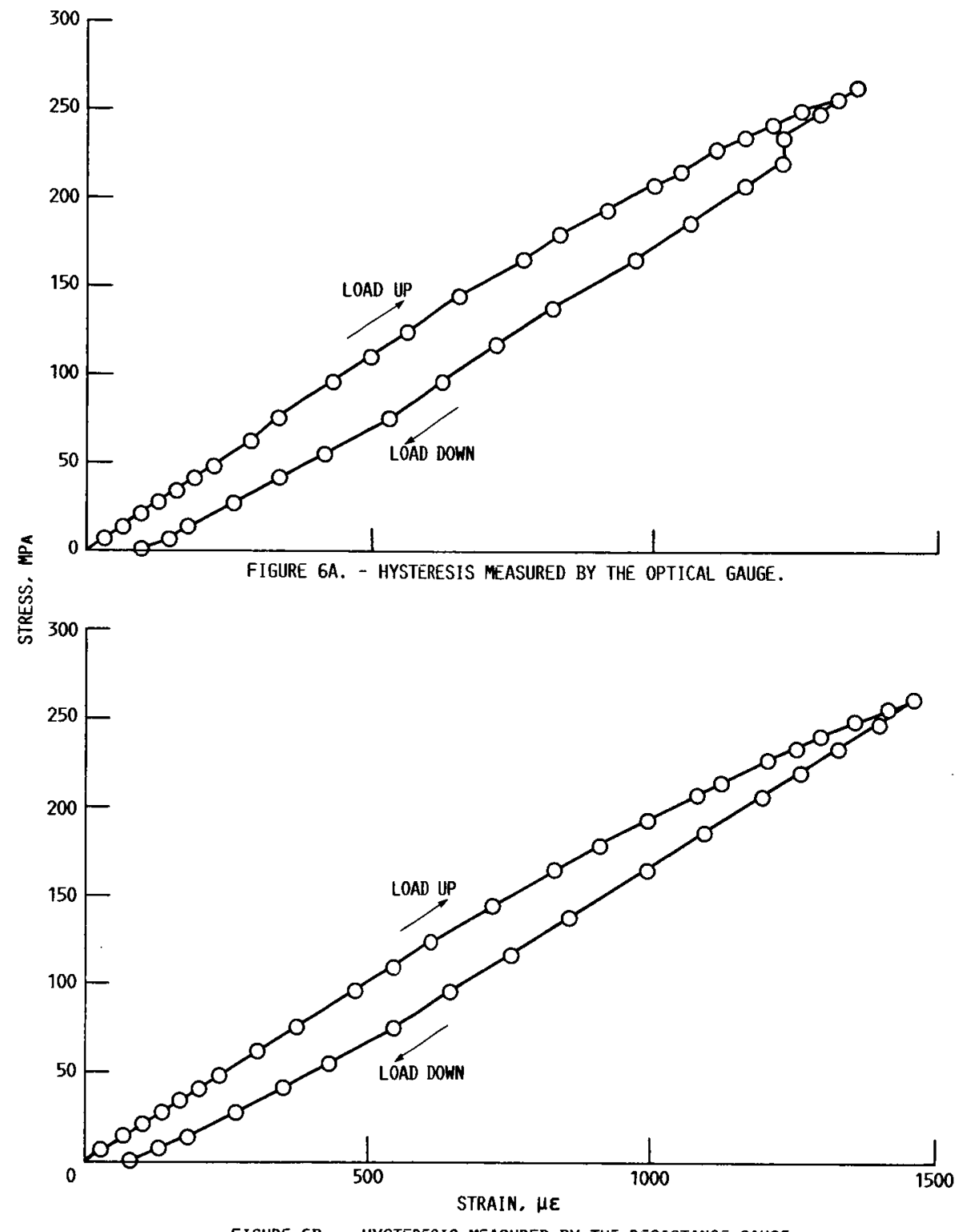

Figure 6B. - hYSTERESIS MEASURED bY tHE RESISTANCE GAUGE. 


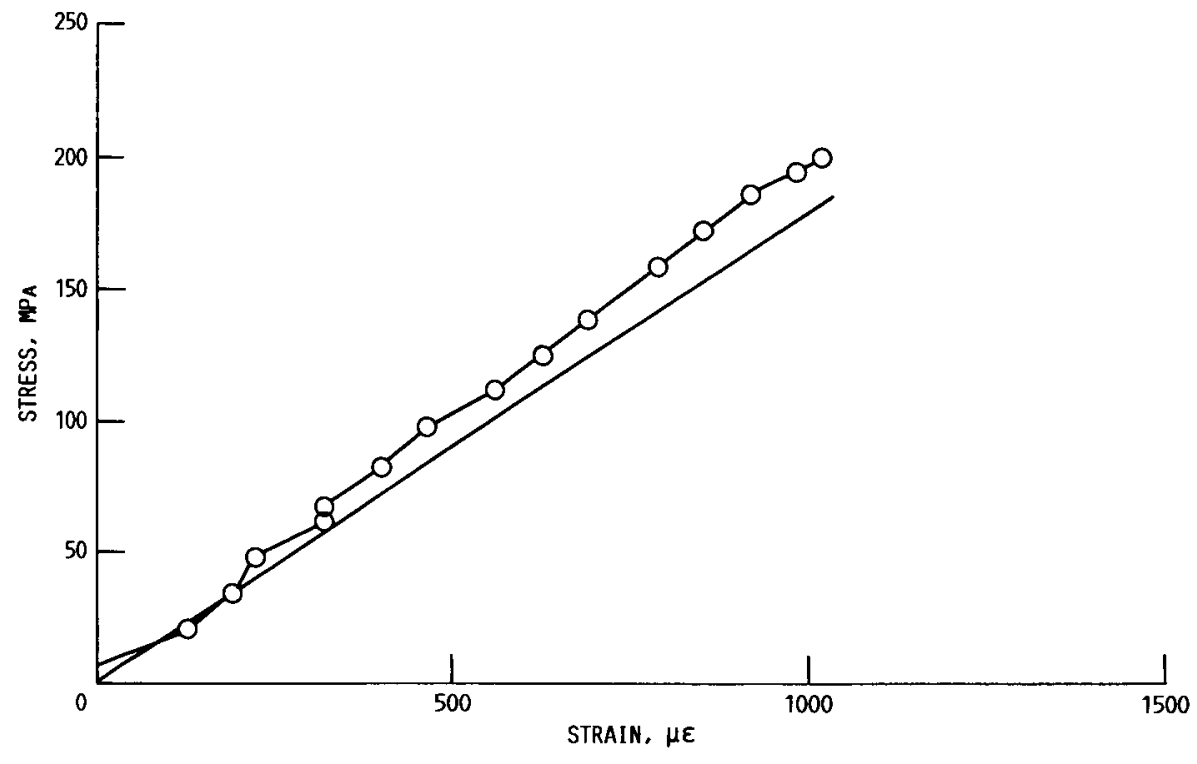

FiguRE 7. - DATA From the OPTICAL gauge at 450 degrees $C$.

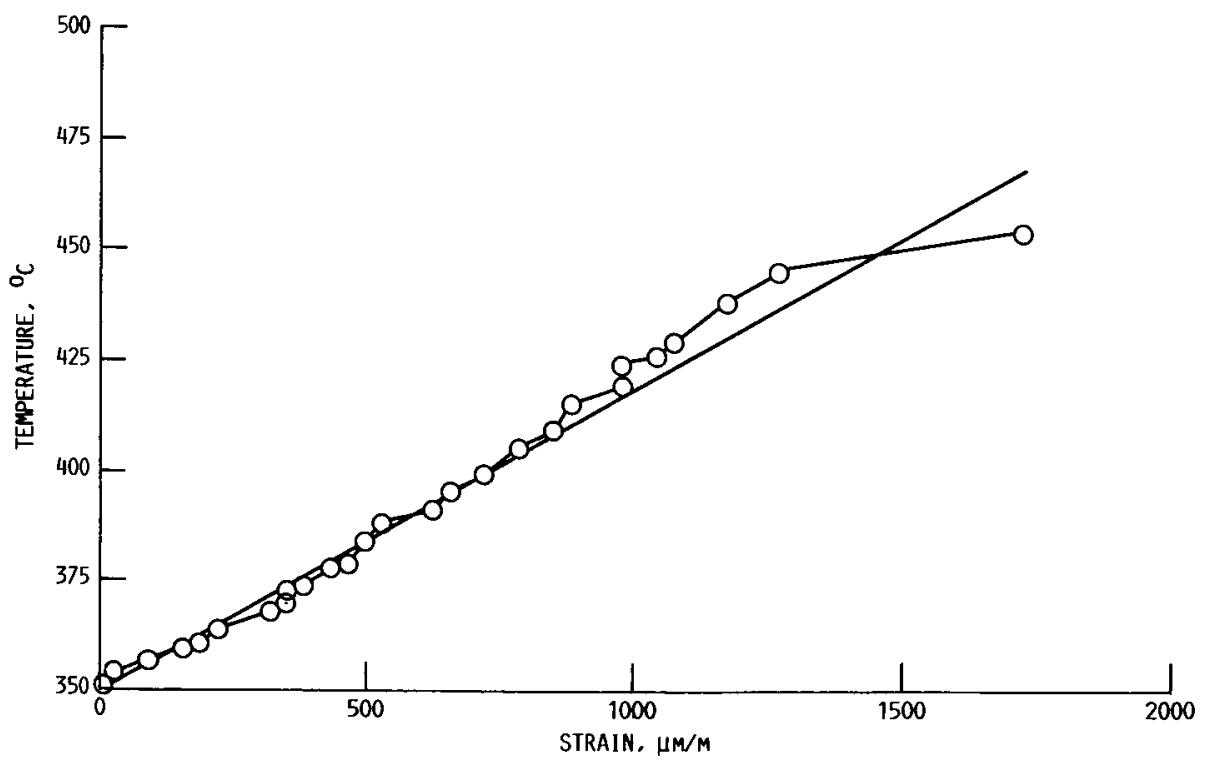

FIGURE 8. - OPTICAL MEASUREMENTS OF THERMAL EXPANSION. THE STRAIGHT LINE INDICATES THE HANDBOOK COEFFICIENT OF THERMAL EXPANSION. 
-XZ POSITIONING table

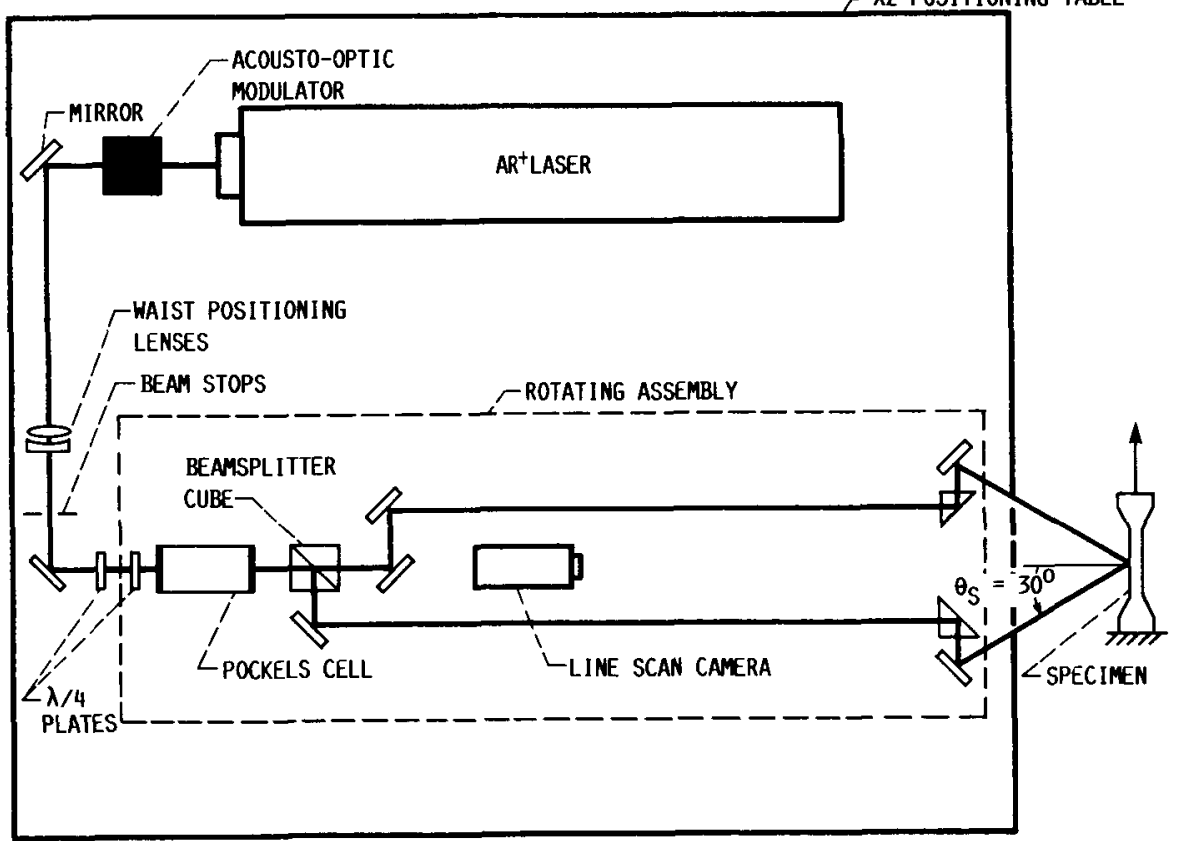

FIGURE 9. - SCHEMATIC OF THE PHASE II OPIICAL DESIGN. 


\begin{tabular}{|c|c|c|c|}
\hline \multicolumn{4}{|c|}{ Report Documentation Page } \\
\hline $\begin{array}{l}\text { RAPort No. } \\
\text { NASA CR-179646 }\end{array}$ & 2. Government Accession No. & \multicolumn{2}{|c|}{ 3. Recipient's Catalog No. } \\
\hline \multirow{2}{*}{\multicolumn{2}{|c|}{$\begin{array}{l}\text { 4. Title and Subtille } \\
\text { Optical Strain Measurement System Development }\end{array}$}} & \multicolumn{2}{|l|}{$\begin{array}{l}\text { 5. Report Date } \\
\text { July } 1987\end{array}$} \\
\hline & & \multicolumn{2}{|c|}{ 6. Performing Organization Code } \\
\hline \multirow{2}{*}{\multicolumn{2}{|c|}{$\begin{array}{l}\text { 7. Author(s) } \\
\text { Christian T. Lant and Walid Qaqish }\end{array}$}} & \multicolumn{2}{|c|}{ 8. Performing Organization Report No. } \\
\hline & & \multicolumn{2}{|l|}{$\begin{array}{l}\text { 10. Work Unit No. } \\
506-42-11\end{array}$} \\
\hline \multirow{2}{*}{\multicolumn{2}{|c|}{$\begin{array}{l}\text { 9. Performing Organization Name and Address } \\
\text { Sverdrup Technology, Inc. } \\
\text { Lewis Research Center } \\
\text { Cleveland, Ohio } 44135\end{array}$}} & \multicolumn{2}{|c|}{$\begin{array}{l}\text { 11. Contract or Grant No. } \\
\text { NAS3-24105 } \\
\end{array}$} \\
\hline & & \multirow{2}{*}{\multicolumn{2}{|c|}{$\begin{array}{l}\text { 13. Type of Report and Period Covered } \\
\text { Contractor Report } \\
\text { Final }\end{array}$}} \\
\hline \multicolumn{2}{|l|}{ 12. Sponsoring Agency Name and Address } & & \\
\hline \multicolumn{2}{|c|}{$\begin{array}{l}\text { National Aeronautics and Space Administration } \\
\text { Lewis Research Center } \\
\text { Cleveland, Ohio } 44135\end{array}$} & \multicolumn{2}{|c|}{ 14. Sponsoring Agency Code } \\
\hline \multicolumn{4}{|c|}{$\begin{array}{l}\text { 15. Supplementary Notes } \\
\text { Project Manager, John P. Barranger, Instrumentation and Control Technology office, } \\
\text { NASA Lewis Research Center. Prepared for 0-E/Fibers '87, A Symposium on Fiber } \\
\text { Optics and Integrated Optoelectronics, sponsored by SPIE - The International } \\
\text { Society for Optical Engineering, San Diego, California, August 16-21, 1987. }\end{array}$} \\
\hline \multicolumn{4}{|c|}{$\begin{array}{l}\text { 16. Abstract } \\
\text { A laser speckle, differential strain measurement system has been built and tested } \\
\text { for future applications in hostile environments. One-dimensional electronic cor- } \\
\text { relation of speckle pattern movement allows a quasi-real time measure of strain. } \\
\text { The system has been used successfully to measure uniaxial strain reaching into } \\
\text { plastic deformation of a test specimen, at temperatures ranging to } 4500^{\circ} \mathrm{C} \text {. } \\
\text { resolution of } 16 \text { microstrain is given by the photodiode array sensor pitch and the } \\
\text { spectmen to sensor separation. The strain measurement error is estimated to be } \\
\pm 18 \text { microstrain } \pm 0.3 \text { percent of the strain reading. The upper temperature } 1 \text { imit of } \\
\text { the gauge is determined by air density perturbations causing decorrelation of the } \\
\text { reference and shifted speckle patterns, and may be improved by } 1 \text { imiting convective } \\
\text { flow in the immediate vicinity of the test specimen. }\end{array}$} \\
\hline \multirow{2}{*}{$\begin{array}{l}\text { 17. Key Words (Suggested by Author(s)) } \\
\text { Laser speck le; High temperature strain } \\
\text { measurement; Correlation; Diffraction; } \\
\text { Refraction }\end{array}$} & \multirow{2}{*}{\multicolumn{3}{|c|}{$\begin{array}{l}\text { 18. Distribution Statement } \\
\text { Unclassified - unlimited } \\
\text { STAR Category } 35\end{array}$}} \\
\hline & & & \\
\hline $\begin{array}{l}\text { 19. Security Classif. (of this report) } \\
\text { Unc lass if f i d }\end{array}$ & & $\begin{array}{c}\text { 21. No of pages } \\
14\end{array}$ & $\begin{array}{r}\text { 22. } \text { Price } \\
\mathrm{A} 02\end{array}$ \\
\hline
\end{tabular}

